\title{
The influence of information and communication technologies in the educational process of the university
}

\author{
Asya Bersirova $^{1, *}$, Fatimet Khakunova ${ }^{1}$, Nurbi Khakunov ${ }^{1}$, Zarema Shkhakhutova ${ }^{1}$, and Ve- \\ ronika Grebennikova ${ }^{2}$ \\ ${ }^{1}$ Adyghe State University, Ulitsa Pervomayskaya, 208, 385000 Maykop, Adyghe Republic, Russia \\ ${ }^{2}$ Kuban State University, Stavropolskaya ulitsa, 149, 350040 Krasnodar, Russia
}

\begin{abstract}
This article summarizes the results of research aimed at studying the impact of the transition to online learning using information and communication technologies (ICT) in the educational process on the psychological comfort of students at the Adyghe State University in the direction of "Psychological and pedagogical education". During the study, a set of complementary research methods was used: theoretical, empirical, statistical, as well as private methods aimed at assessing the level of anxiety, sociability, motivation for learning, and the questionnaire aimed at identifying the level of psychological comfort of students in online learning. We suspected that the transition to online learning can affect the psycho-emotional state and psychological comfort of students: trait and state anxiety will increase; the level of motivation for learning, and the level of students' communicative activity will decrease. Analysis and interpretation of the data showed that in the process of online learning, the majority of the tested respondents were dominated by average and high values of situational and personal anxiety ( $43.9 \%$ and $47.9 \%$, respectively). $59 \%$ of respondents faced psychological discomfort because of the necessary to sharply adapt to the new format of education. There were also difficulties with self-organization of learning process outside the university $-21.7 \%$, as well as difficulties associated with the material and technical base, created an uncomfortable psycho-emotional state in the subjects of the educational process - 3.5\%. Therefore, in introducing online learning, it is necessary to take into account several possible risks that affect both the quality of the learning process and the psycho-emotional state of students. Moreover, a necessary condition, in our opinion, is considering the individual and personal characteristics of students in the process of integrating ICT into the educational system to improve health and create conditions for the psychological comfort of students.
\end{abstract}

\section{Introduction}

\footnotetext{
*Corresponding author: asya.bersirova@mail.ru
} 
The era of global digitalization (Information and Communication Technologies) has affected almost all aspects of our world and influenced the lifestyle of adults and children [1]. The higher education system is also actively and widely introducing ICT, trying to be attributable to the demand of modern society in preparing competitive specialists for future professional activities in the face of challenges, opportunities, and advantages of new technologies [2]. The situation of the pandemic has accelerated the process of introducing ICT into educational practice, which appeared several difficulties associated with the unavailability and insufficient material and technical equipment of both the university itself and all participants in the educational process. This could affect psychological comfort, cause fear and anxiety in the learning process of students, affect their level of motivation, and change communication activities.

The rapid advances in information and communication technologies (ICT) have changed our way of life, affecting all its aspects. In education, ICT helps to assist both students and teachers. Information and communication technologies allow the collection, production, storage and processing, transmission, recording, and presentation of information in the form of images, voice, and text messages [2].

Digital technologies imply not only an adaptation to new forms of interaction, but also a change in the learning paradigm. In this sense, there is not a single university in the world that no longer has a digital platform. Moreover, the introduction of e-learning makes the process fun and exciting, which increases the level of motivation. Educational ICT is on par with traditional learning, but it also offers advantages for teaching and learning flexibility [3].

Some authors prefer to argue directly that it is necessary to connect to learning through interactions in social networks. Research on the role of social networks as one of the ways to increase motivation to seek new knowledge and productive communication, the desire to comprehend new things opens up a new understanding of the value of communication, including online interaction [4]. Numerous existing websites allow active collaboration for joint assignments and projects [5]. For example, the WIKI platform is productively used when students are simultaneously present and work directly through active interaction with their teammates, classmates, teachers, or leaders to improve the learning experience and achieve results [6]. The use of social media in higher education has been expanding in recent years, trying to establish connections and new ways of communicating among students or pedagogies [7, 8]. Besides, the Bologna Process provides for the assessment of competencies as a novelty in the assessment process in higher education and includes ICT competencies as an important factor in student development. ICT competencies, also known as ICT literacy, include knowledge, skills, and ability to use a computer, word processing, spreadsheet, database, file management, documentation, presentation, and communication [9].

Technology can make our lives easier and simplify our daily tasks. The use of social media in higher education is becoming a new form of communication with students, and educators can use these new tools for a variety of purposes. Moreover, an important factor is the motivation of students to use the online environment - this is the opportunity to demonstrate their own abilities and creativity [2].

Research by Nicoleta Duţă, Oscar Martínez-Rivera (2015) draws attention to the increased role of the teacher in new cultural and educational environments that are and will be created through information technology and communications [2].

Researches about the special aspects of the organization of educational spaces have shown that students prefer the study space at home for individual lessons, and for joint studying activities with their peers, they prefer the study space at the university. It has also been 
highlighted that public spaces are not popular for studying [10]. Research data indicate the students' need for active offline communication with peers in the learning process.

Online education is quite often used in university systems [11]. There is a growing demand for the introduction of information and communication technologies (ICT) in the educational and methodological process. However, the success of projects aimed at achieving this goal depends on how positively pedagogues and students will view these forms of education.

Lack of anxiety, fear, negative feelings and thoughts, peace of mind, and self-confidence - all this forms a psychological comfort. This state allows the student to feel like a healthy and happy person, motivated to successfully master the educational program and acquire knowledge, skills, and abilities. One of the strategic tasks of the educational environment of the university is precisely the maintenance of the psychological comfort of students and pedagogues.

Researches aimed at studying the emotional sphere of students in the context of the digitalization of the university environment (Batietal., 2018; Karatasetal., 2016; Romo-Barrientosetal., 2019) emphasized that health concerns are characteristic of a large number of people. Higher education students are trying to adapt to the new university environment. They are experiencing some difficulties related to financial problems, adaptation to university life, and conditions, as well as the establishment of new social ties. All this inevitably affects physical and mental health [12]. Reducing students' anxiety levels can improve learning and learning success. The most obvious example of reducing anxiety is using gamification as a teaching element (Hamariand Koivisto, 2013). In them, players can acquire skills and knowledge in an environment characterized by comfort and well-being. For its part, gamification is known as a process involving the mindset of the players and gaming techniques to engage users and solve problems (Zichermannand Cunningham, 2011). Any game implicit in the concept of gamification should not only influence the psychological and social behavior of the player but also help to find answers to certain problems. The more they play, the more time is spent on improving comfort [13]. It is important to understand the difference between learningbased play and gamification, and between gamification using educational games in the classroom [14]. The first is a pleasant environment in the context of voluntary learning using incentives such as scores, ranking, etc., and, according to some authors (Hernández-Santaolalla, 2009), (Jurkovič, 2019), the use of mobile applications can be an excellent learning opportunity, thanks to the connectivity and mobility that facilitates access to resources [15]. Almost every modern student has at hand a mobile phone connected to the Internet, which gives him unhindered access to the system of the online education platform of the university, regardless of time and place. This creates greater comfort in the transition to online learning, both materially and psychologically. It becomes possible to independently determine the trajectory of the educational process, developing volitional qualities and self-organization.

A certain influence on the formation of personality is exerted by the peculiarities of the use of ICT in the educational process. Therefore, an important condition for the effectiveness of an individual approach in the educational and educational environment of a university is close attention to creating conditions for maintaining psychological well-being, emotional stability, and the development of students' ability to self-education and self-development. To direct the activity of each subject in the right direction - to the knowledge of other people, to self-development and self-education, to communicative activities and high motivation in acquiring knowledge is the main task of the educational process. The solution to this problem is possible only if the determinants of achieving psychological comfort and sustainable motivation in the learning process with the use of ICT are sufficiently fully studied, which determines the relevance of the topic under study. 
During work on the study, we identified the main contradictions:

- The contradiction between the necessity of modern reality in the active use of ICT in the learning process and the insufficient study of the issue of the impact of digital education on the health of students;

- The contradiction between the need to develop criteria for assessing the feasibility and effectiveness of online learning and the lack of fundamental research on the problem of psychological and pedagogical risks of digitalization of education.

The contradictions highlighted by us allowed us to formulate the research problem: what are the features of the influence of digitalization of education on the psychological comfort of students?

The research aims to study the impact of the transition to online learning using information and communication technologies (ICT) on the psychological comfort of students at the Adyghe State University in the direction of "Psychological and pedagogical education".

Research objectives:

- to determine the state of the investigated problem in psychological and pedagogical theory;

- identify the level of trait and state anxiety during online education;

- determine the level of psychological comfort of students;

- determine the level of motivation for the education of students;

- study the features of communication activity.

The object of research: bachelors in the direction of training "Psychological and pedagogical education".

Subject of research: the impact of online learning on psychological comfort, communication activity, and motivation of students' learning.

In our study, we proceeded from the hypothesis that the introduction of information and communication technologies into the educational environment affects the psychological comfort of students: personal and situational anxiety increases the level of motivation for learning and communicative activity decreases.

\section{Materials and Methods}

Based on the goal and the hypothesis put forward, the following tasks were set in the scientific research:

1. To reveal the theoretical aspects and to characterize the peculiarities of the ICT influence on the psychological comfort of students.

2. To select and substantiate a complex of diagnostic methods for the study of educational motivation, the level of anxiety, and communicative activity of student youth.

3. Identify determinants and risk factors

To solve the set tasks, the following methods were used in the research process:

- theoretical - analysis, synthesis, and generalization of research results in psychological and methodological literature on the research problem;

- empirical - observation, conversation testing, analysis of products of activity, psychological experiments;

- statistical - analytical processing and interpretation of experimental data.

The following techniques were used:

1. Spielberger's State-Trait Anxiety Inventory (STAI);

2. Methods of studying the motivation for teaching students (T.I. Ilyina).

3. Assessment of the general level of sociability (V. F. Ryakhovsky) 
4. The author's questionary aimed at identifying the level of psychological comfort of the student in the educational environment of the university in the context of online education. The research involved 198 students (bachelors) of the Faculty of Pedagogy and Psychology of the Federal State Budgetary Educational Institution of Higher Education of the Adyghe State University. The study was conducted in 2020 during the transition to online learning due to the pandemic.

\section{Results}

The survey data on identifying psychological comfort in the process of switching to online learning showed that 117 students $(59 \%)$ have difficulties in adapting to the new conditions of using information and communication technologies in education. The main reasons that were identified are a decrease of interest in the studied discipline $(31.8 \%)$, lack of skills to work on remote platforms $(24.2 \%)$, difficulties in self-organization $(21.7 \%)$, unstable Internet connection $(6,6 \%)$, lack of appropriate material and technical equipment and software (3.5\%). The question "is it comfortable to study remotely?" was answered positively by 83 respondents. However, they indicated a preference in favor of classroom studies, which amounted to $41.9 \%$ of the total number of respondents. The analysis of the responses has shown that the presence of the teacher doesn't stimulate students' learning activities if it takes place online.

Thus, students are focused on face-to-face classroom studies with partial use of information and communication technologies in the learning process. For most respondents, working offline with a teacher results in more positive emotions than doing independent work on a flexible schedule.

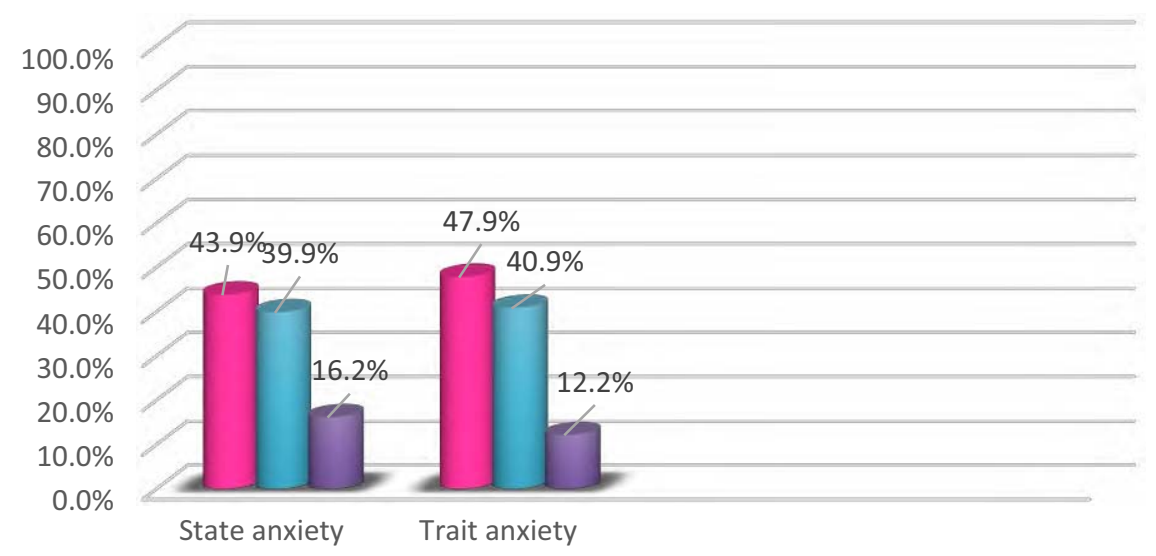

high level middle level low level

Fig. 1. Research results of personal and situational anxiety.

Researches of students' trait and state anxiety during the period of online learning showed that $79(39.9 \%)$ respondents have an average level of state anxiety. Young people attach particular importance to certain elements of the situation or find resources and opportunities to control their emotional experiences. Such students try to objectively assess the emerging 
situations. However, they feel insecure in their abilities in the initial stages. Thus, there is a short-term and insignificant violation of the emotional balance, a decrease in a working capacity.

High levels of state anxiety was shown by $87(43,9 \%)$ respondents, which points out that regarded situations are extremely important for them. Student feels tension, anxiety, muscle stiffness. There is a complete concentration on what is happening, which seems dangerous and overwhelming. As a result, there is dissatisfaction with oneself, other people, withdrawal from social communication.

A low level was found in only 32 students (16.2\%). This level of anxiety shows the insufficiently high significance of a particular situation in which the respondent finds himself at the time of the survey. A person with this level of anxiety is self-confident, internally relaxed, satisfied with himself, his condition, situation. He is tuned in to successfully overcome obstacles and feels enough strength in himself for this.

A high level of trait anxiety was found in $95(47.9 \%)$ respondents. This means that most of the situations in which the student finds himself are perceived as threatening him, his prestige or self-esteem. 81 students $(40.9 \%)$ have an average level: at which a person feels comfortable, maintains emotional balance and working capacity. The situations seem to be mostly familiar, the individual successfully adapts to them, realizing his responsibility and possible consequences. When the situation gets worse, anxiety can appear. Only 22 students $(12.2 \%)$ have a low level of trait anxiety. As a rule, such people perceive the emerging difficulties adequately to their objective emotional saturation.

In the course of the study of the motivation of students' learning process during the period of online learning, it was revealed that external motives of learning such as "obtaining a diploma" and "mastering a profession" prevail over internal "gaining knowledge". First of all, this shows formal attitude towards the educational process itself, a decrease in interest in acquiring knowledge. This is probably due to the lack of emotional live communication with the teacher, as well as difficulties in the independent mastering of new educational material, the difficulties of imperfect assessment systems in conditions of online work.

According to the indicator of the level of communication skills of the studied group, we can conclude that the decrease in live communication during the period of online learning influenced the communication activity in general. Despite the fact that the majority of the respondents have normal indicators of sociability (45.9\%), the values of the low level of sociability out of the total number of respondents turned out to be quite high $(36.9 \%)$.

Thus, the results of the study show a significant predominance of medium and high levels of anxiety, a decrease in the level of motivation for learning and communication activity among students of the Adyghe State University during the transition to online learning using information and communication technologies (ICT).

\section{Discussion}

One of the signs of a high level of organization of the educational process of the 21 st century is the presence and active use of information and communication technologies (ICT) in universities. However, it is necessary to take a differentiated approach to the inevitable transformation of the modern education system in connection with the transition to online learning. A number of studies show that mastering an educational program is much more effective when using information and communication technologies (ICT) in the educational process. During our research, we found that a complete transition to online learning causes changes in the psycho-emotional state of students. The most numerous category of significance of 
both trait and state anxiety falls on the high level of indicators (47.9\% and $43.9 \%$, respectively). The study identified several problems associated with the psycho-emotional state of the subjects of the educational process in the format of online learning:

- digitalization of education increases the level of anxiety of subjects of the educational process;

- when switching to online learning, interest and motivation, self-organization and desire to engage in self-education tend to decrease;

- the communicative activity of students decreases;

- psychological comfort and emotional stability of the subjects of the educational process is disturbed.

Thus, the task of the teaching staff of the university is to find ways to overcome this effect in order to maintain psychological comfort and preserve mental health through the realization and implementation of effective forms of online learning. In our opinion, the organization of the educational process at the university should combine the optimal balance between the use of information and communication technologies (ICT) and traditional teaching technologies. This should include the creation of conditions for the development of the ability for selfeducation and self-improvement of students, considering the implementation of the competence-based approach and the requirements of the professional standard. Such tasks can form the basis for future research in this area.

\section{Conclusions}

The analysis of theoretical studies showed that there are no fundamental studies that would identify the existing risks and determinants for the physical and mental health of a person in the context of the introduction of digitalization into education.

The revealed data indicate that in the process of online learning, students have an increased trait and state anxiety, a decrease in interest in the educational process, difficulties in self-organization and motivation of learning.

The organization of the educational process using information and communication technologies (ICT) requires the creation of the necessary conditions to maintain psychological comfort and preserve the health of students.

\section{References}

1. S. Martin, G. Diaz, E. Sancristobal, R. Gil, M. Castro, J. Peire, New technology trends in education: Seven years of forecasts and convergence. Computers \& Education, 57(3), 1893-1906 (2011) doi: 10.1016/j.compedu.2011.04.003

2. N. Duţă, O. Martínez-Rivera, Between Theory and Practice: The Importance of ICT in Higher Education as a Tool for Collaborative Learning. Procedia - Social and Behavioral Sciences, 180, 1466-1473 (2015) doi: 10.1016/j.sbspro.2015.02.294

3. L. Webb, J. Clough, D. O'Reilly, D. Wilmott, G. Witham, The utility and impact of information communication technology (ICT) for pre-registration nurse education: A narrative synthesis systematic review. Nurse Education Today, 48, 160-171 (2017) doi: 10.1016/j.nedt.2016.10.007

4. J. M. Carpenter, M. C. Green, J. LaFlam, People or profiles: Individual differences in online social networking use. Personality and Individual Differences, 50(5), 538-541 (2011) doi: 10.1016/j.paid.2010.11.006 
5. J. P. Carpenter, R. Kimmons, C. R. Short, K. Clements, M. E. Staples, Teacher identity and crossing the professional-personal divide on twitter. Teaching and Teacher Education, 81, 1-12 (2019) doi: 10.1016/j.tate.2019.01.011

6. M. M. Luo, S. Chea, Wiki use for knowledge integration and learning: A three tier conceptualization. Computers \& Education, 154, 103920 (2020) doi: 10.1016/j.compedu.2020.103920

7. G. Veletsianos, R. Kimmons, Scholars in an increasingly open and digital world: How do education professors and students use Twitter? The Internet and Higher Education, 30, 1-10 (2016) doi: 10.1016/j.iheduc.2016.02.002

8. M. D. Roblyer, M. McDaniel, M. Webb, J. Herman, J. V. Witty, Findings on Facebook in higher education: A comparison of college faculty and student uses and perceptions of social networking sites. The Internet and Higher Education, 13(3), 134-140 (2010) doi: 10.1016/j.iheduc.2010.03.002

9. J. Copriady, Self-motivation as a Mediator for Teachers' Readiness in Applying ICT in Teaching and Learning. Procedia - Social and Behavioral Sciences, 176, 699-708 (2015) doi: 10.1016/j.sbspro.2015.01.529

10. R. Beckers, T. van der Voordt, G. Dewulf, Learning space preferences of higher education students. Building and Environment, 104, 243-252 (2016) doi: 10.1016/j.buildenv.2016.05.013

11. M. C. Gallego Sánchez, C. De-Pablos-Heredero, J. A. Medina-Merodio, R. RobinaRamírez, L. Fernandez-Sanz, Relationships among relational coordination dimensions: Impact on the quality of education online with a structural equations model. Technological Forecasting and Social Change, 166, 120608 (2021) doi: 10.1016/j.techfore.2021.120608

12. K. Chaturvedi, D. K. Vishwakarma, N. Singh, COVID-19 and its impact on education, social life and mental health of students: A survey. Children and Youth Services Review, 121, 105866 (2021) doi: 10.1016/j.childyouth.2020.105866

13. M. Hatzigianni, A. Gregoriadis, M. Fleer, Computer use at schools and associations with social-emotional outcomes - A holistic approach. Findings from the longitudinal study of Australian Children. Computers \& Education, 95, 134-150 (2016) doi: 10.1016/j.compedu.2016.01.003

14. Z. Zainuddin, C. Kai Wah, S. M. Shujahat, C. J. Perera, The impact of gamification on learning and instruction: A systematic review of empirical evidence. Educational Research Review, 30, 100326 (2020) doi: 10.1016/j.edurev.2020.100326

15. S. Paniagua, R. Herrero, A. I. García-Pérez, L. F. Calvo, Study of Binqui. An application for smartphones based on the problems without data methodology to reduce stress levels and improve academic performance of chemical engineering students. Education for Chemical Engineers, 27, 61-70 (2019) doi: 10.1016/j.ece.2019.03.003 